\title{
Sensitization to cereals and peanut evidenced by skin prick test and specific lgE in food-tolerant, grass pollen allergic patients
}

Maria Martens, Heidi J Schnoor, Hans-Jørgen Malling and Lars K Poulsen*

\begin{abstract}
Background: The botanical relation between grass and cereal grains may be relevant when diagnosing food allergy to cereals. The aim was to investigate the diagnostic specificity of skin prick test (SPT) and specific immunoglobulin E (slgE) tests to cereals and peanut in grass pollen allergic subjects without history of, and clinically reactions to foods botanically related to grass.
\end{abstract}

Methods: 70 subjects ( 41 females; mean age 32 years) and 20 healthy controls (13 females; mean age 24 years) were tested by open food challenge (OFC) with cereals and peanut. SPT and slgE both with Immulite ${ }^{\circledR}$ (Siemens) and ImmunoCAP ${ }^{\circledR}$ (Phadia) to grass and birch pollen, cereals, peanut and bromelain were performed.

Results: Of the 65 OFC-negative subjects 29-46\% (SPT, depending on cut-off), 20\% (Immulite) and 38\% (ImmunoCAP) had positive results to one or more of the foods tested. Controls were negative in all tests. Crossreactive carbohydrate determinants (CCD) as evidenced by reaction to bromelain could explain only a minority of the measured lgE-sensitizations.

Conclusion: Grass pollen allergic patients with documented food tolerance to cereals and peanut may express significant sensitization. False-positive cereal or peanut allergy diagnoses may be a quantitatively important problem both in routine clinical work and epidemiological studies.

Keywords: Cereals, cross-reaction, diagnosis, food challenge, grass pollen allergy

\section{Introduction}

Wheat IgE-mediated allergy manifests itself as food allergy [1] and as occupational inhalant allergy (Baker's asthma) [2] and identical allergens seem to be responsible in both allergies, although their relative importance differ $[3,4]$. It is a general clinical experience that also patients without these diseases may display positive skin test or immunoglobulin E (IgE) towards wheat and the cross-reactivity between grass pollen and cereals may have an impact on the specificity of the diagnostic tests [1,5-7].

In a non-published retrospective study performed in our department we found a large number of positive reactions to cereals in specific IgE (sIgE) tests in grass pollen allergic patients claiming to tolerate cereals, when interviewed by telephone. Also Jones et al. [8]

\footnotetext{
* Correspondence: Ikpallgy@mail.dk

Allergy Clinic, Copenhagen University Hospital, Gentofte, Denmark
}

found clinically non-relevant reactions to cereals in grass pollen allergic patients. Low specificity of cerealrelated diagnostic tests is a particular problem since grass pollen allergy is very prevalent compared to true cereal allergy, but studies of grass pollen allergic subjects with clinical tolerance to cereals confirmed by food challenge are scanty. False positive tests may result in overestimation of cereal allergy prevalence in epidemiological studies, and on the individual level lead to unwarranted dietary restrictions or unnecessary doubleblind, placebo-controlled food challenges (DBPCFC).

Our aim was to investigate the diagnostic specificity, i. e. number of false positives, of skin prick test (SPT) and sIgE tests to cereals and peanut in a group of grass pollen allergic subjects without history of and clinically reactions to foods botanically related to grass. This was done in a prospective study where tolerance to cereals and peanut in grass pollen allergic subjects was verified 
by a negative food challenge and the correlation between two different SIgE tests was investigated. While botanically unrelated to cereals, we also looked into the cross-reactivity between peanut and grass pollen. Studies have shown a clinically irrelevant association between grass and peanut [9-12], and we know that a positive test to peanut may alarm patients and clinicians.

\section{Materials and methods}

\section{Study population}

Recruitments were made by advertising in local newspapers for persons with a history of grass pollen allergy but no clinical reaction including exercise-induced anaphylaxis to cereals and peanut. Healthy control persons were also recruited. Inclusion criteria were: Age 18-60, history of allergy to grass pollen, positive SPT and SIgE (ImmunoCAP) level to grass pollen $\geq 0.70 \mathrm{kU}_{\mathrm{A}} / \mathrm{L}$. No allergy related medicine was allowed for at least five days before the visits and all subjects must have a $\mathrm{FEV}_{1}$ $\geq 80 \%$ of the expected value. Exclusion criteria were: pregnancy, breast-feeding, known allergies to cereals or peanut. Neither previous nor ongoing grass immunotherapy, nor allergy to other inhalant allergens or foods cross-reacting with birch constituted exclusion criteria.

The local Ethics Committee approved the study (H-D2008-072) and informed consent was obtained from all subjects.

\section{Food challenge}

Since the suspected outcome of challenges was confirmation of tolerance these were performed openly (OFC). Raw wheat, rye, barley, oat, maize, rice (all as flakes) and salted peanuts were administered in dose of $25 \mathrm{~g}$ each; all seven foods were consumed directly after one another, producing a total meal dose of $175 \mathrm{~g}$ and were consumed within half an hour. Addition of sugar, cow's milk, or soymilk was allowed. There were no restrictions regarding the diet in the days before the challenge. All subjects were observed for 2 hours, and any subjective and/or objective symptoms were recorded. Giving the test meal as single dose, with all seven foods without intervals, prevented us from further examining the positive reactions, and to identify to which food or threshold dose they occurred. For some the large dose might represent a large meal and could cause reactions they were not used to; e.g. satiety-related symptoms. Known asthmatics were monitored by $\mathrm{FEV}_{1}$ during the observation period.

\section{Skin prick test}

Both allergics and controls underwent SPT with commercial extracts (Soluprick ${ }^{\circledR}$, ALK-ABELLO, Hørsholm, Denmark) for a panel of common inhalation allergens
(Table 1). Freshly made suspensions of flour and saline $(1: 10)$ were used for SPT with cereals (wheat, rye, oats, barley, maize and rice). SPT with peanut was made as prick-prick [13]. SPT was performed in duplicates on the volar aspect of the forearm including positive control (histamine dihydrocloride $(10 \mathrm{mg} / \mathrm{ml})$ ) and negative control (Soluprick solution). The area of the weal was outlined with a pen, transferred to a record form and scanned [14]. For the standardized extracts of inhalation allergens the cut off was $7 \mathrm{~mm}^{2}$, corresponding to a wheal diameter of $3 \mathrm{~mm}$, whereas for the foods no cut off was applied. There were no reactions to the negative control and none with dermographism. The results were expressed as the mean of the duplicates.

\section{Specific lgE}

All subjects and controls were tested for sIgE antibodies according to the producers' instructions on both the CAP-FEIA (ImmunoCAP ${ }^{\circledR}$ 250, Phadia, Uppsala, Sweden) and the Immulite (Immulite ${ }^{\circledR} 25003 \mathrm{~g}$ Allergy, Siemens Healthcare Diagnostics, Deerfield, IL, US). The allergens tested were grass (g6), birch (t3), wheat (f4), rye (f5), oat (f7), barley (f6), maize (f8), rice (f9), peanut (f13) and bromelain (k202). All sample measurements

Table 1 Patients and controls demographics, sensitization status to inhalant allergens and asthma status.

\begin{tabular}{lcc}
\hline & $\begin{array}{c}\text { Allergic } \\
\text { subjects }\end{array}$ & Controls \\
\hline Mean age (years) & 32 & 24 \\
- range & $18-57$ & $21-30$ \\
Females & 38 & 13 \\
Males & 27 & 7 \\
No. of patients sensitized (skin prick test) & & \\
to inhalant allergens: & & \\
Grass (inclusion criterion) & 65 & 0 \\
Birch & 26 & 0 \\
- history of birch pollen allergy & 24 & 0 \\
- plus allergy to foods cross-reacting with birch & 14 & 0 \\
Mugwort & 20 & 0 \\
Dog & 34 & 0 \\
Cat & 24 & 0 \\
Horse & 2 & 0 \\
D. pteronyssinus & 26 & 0 \\
D. farinae & 17 & 0 \\
Alternaria & 9 & 0 \\
Cladosporium & 5 & 0 \\
Asthma status: & & \\
Seasonal & 5 & 0 \\
Perennial & 5 & 0 \\
Mean onset age (years) & 57 & - \\
Outgrown asthma & 5 & 0 \\
\hline
\end{tabular}


were performed in duplicates and results $>0.35 \mathrm{kU}_{\mathrm{A}} / \mathrm{l}$ (expressed as mean) were considered positive.

\section{Results}

Study population and open food challenge

Seventy subjects and 20 controls were tested by OFC and five subjects had a positive challenge test and were therefore excluded. The five reactors had symptoms of oral allergy syndrome, feeling of weight on the chest, feeling of swelling in throat, itch in the scalp and palms and rhinitis. All symptoms were mild and subjective only and cleared within the observation period after antihistamine $(n=1)$, bronchodilator $(n=1)$ or spontaneously $(\mathrm{n}=3)$. The five reacting subjects were offered further investigation of their reactions by a new challenge, but only one accepted. Four of the five with positive OFC had a positive SPT to one or more of the foods tested.

All 20 controls had a negative OFC and negative SPT and IgE-tests to all inhalants and foods. Patients and controls demographics, sensitization status to inhalant allergens and asthma status are listed in Table 1. Most $(83 \%)$ of the 65 patients had experienced grass-pollenrelated symptoms for more than five years.

\section{Skin testing with foods}

Thirty subjects (46\%) had positive SPT to one or more of the foods tested. Excluding peanut, this gives $45 \%$ positives to any cereal. $9 \%$ reacted to peanut. The wheal size of SPT reactions to cereals and peanut was 5 times smaller than the wheal size for grass (Figure 1A). Subjects reacted most frequently to wheat, rye and barley (25 reactions to barley and 23 reactions to both wheat and rye, compared with 7, 5, 8 and 6 reactions to oat, maize, rice and peanut respectively). The number of positives would be remarkably reduced if the cut off at $7 \mathrm{~mm}^{2}$ were applied, and the percentages being positive to at least one cereal would be reduced to $29 \%$.

\section{Specific IgE by Immulite and ImmunoCAP}

The number of subjects used for analyses of the Immulite results was reduced to 64 because of lack of serum from one subject who was therefore excluded from further analysis. The number of positive subjects was below 10 for all the foods and bromelain. In total 20\% reacted to at least one of the foods tested. Twenty percent were positive to one or more cereals and $13 \%$ to peanut. In contrast to the SPT and ImmunoCAP results, less subjects sensitized to wheat, rye and barley were detected, nor did the Immulite identify any subjects sensitized to oat (Figure 1B).

In ImmunoCAP as in SPT, there was a majority reacting to wheat, rye and barley, but also many positive peanut reactions (Figure 1C). The percentages of positives

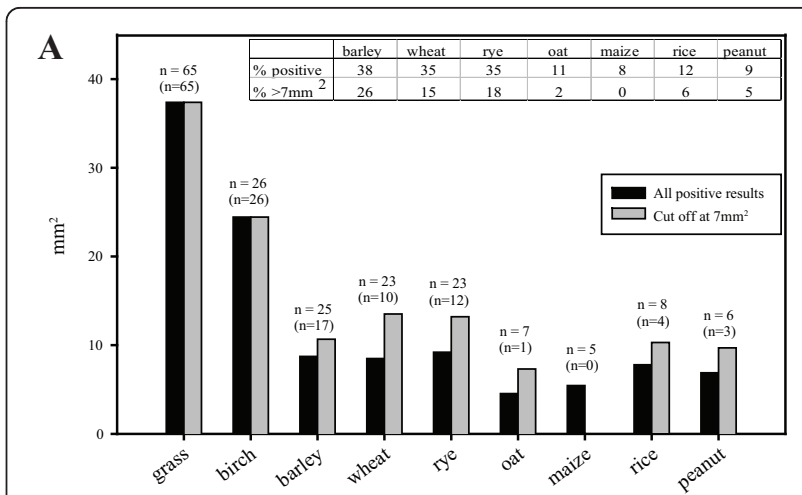

B

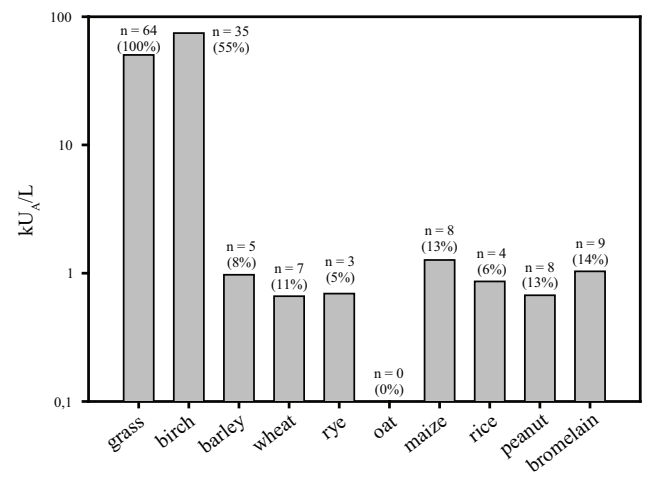

C

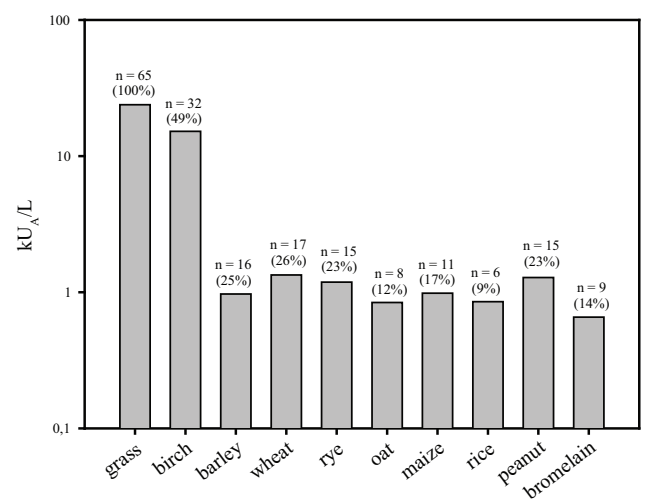

Figure 1 Positive results of SPT and slgE. A. SPT mean wheal sizes of positive results. $n=$ number of positives. Number of positive results $>7 \mathrm{~mm}^{2}$ in parentheses. The inserted table shows percentages of positives with or without application of $7 \mathrm{~mm}^{2}$ as cut off. B. Immulite, means of positive slgE results $>0.35 \mathrm{kU} \mathrm{A}_{\mathrm{A}} / \mathrm{L}$ on log-scale. Percent positive in parentheses. C. ImmunoCAP, means of positive slgE results $>0.35 \mathrm{kU}_{\mathrm{A}} / \mathrm{L}$ on log-scale. Percent positive in parentheses.

were $38 \%$ to any of the foods tested, $32 \%$ to at least one cereal and $23 \%$ to peanut. The mean levels of sIgE to cereals and peanut were typically 40 times lower than to grass and birch both in Immulite and ImmunoCAP.

Immulite detected fewer positive reactions than ImmunoCAP. There was a low degree of correlation 
between the two tests, but those that correlated were in the same level around $1 \mathrm{kU}_{\mathrm{A}} / \mathrm{L}$ (Figure 2). As for rye, oat and peanut the Immulite did not identify any other than those identified by the ImmunoCAP. The concordance ranged from 0.77-0.91.

\section{Relationship between foods}

Positive reactions to the different foods showed comparable patterns in SPT and sIgE results. These clinically non-relevant sensitizations could be divided into three groups. Group I: subjects sensitized to wheat, rye
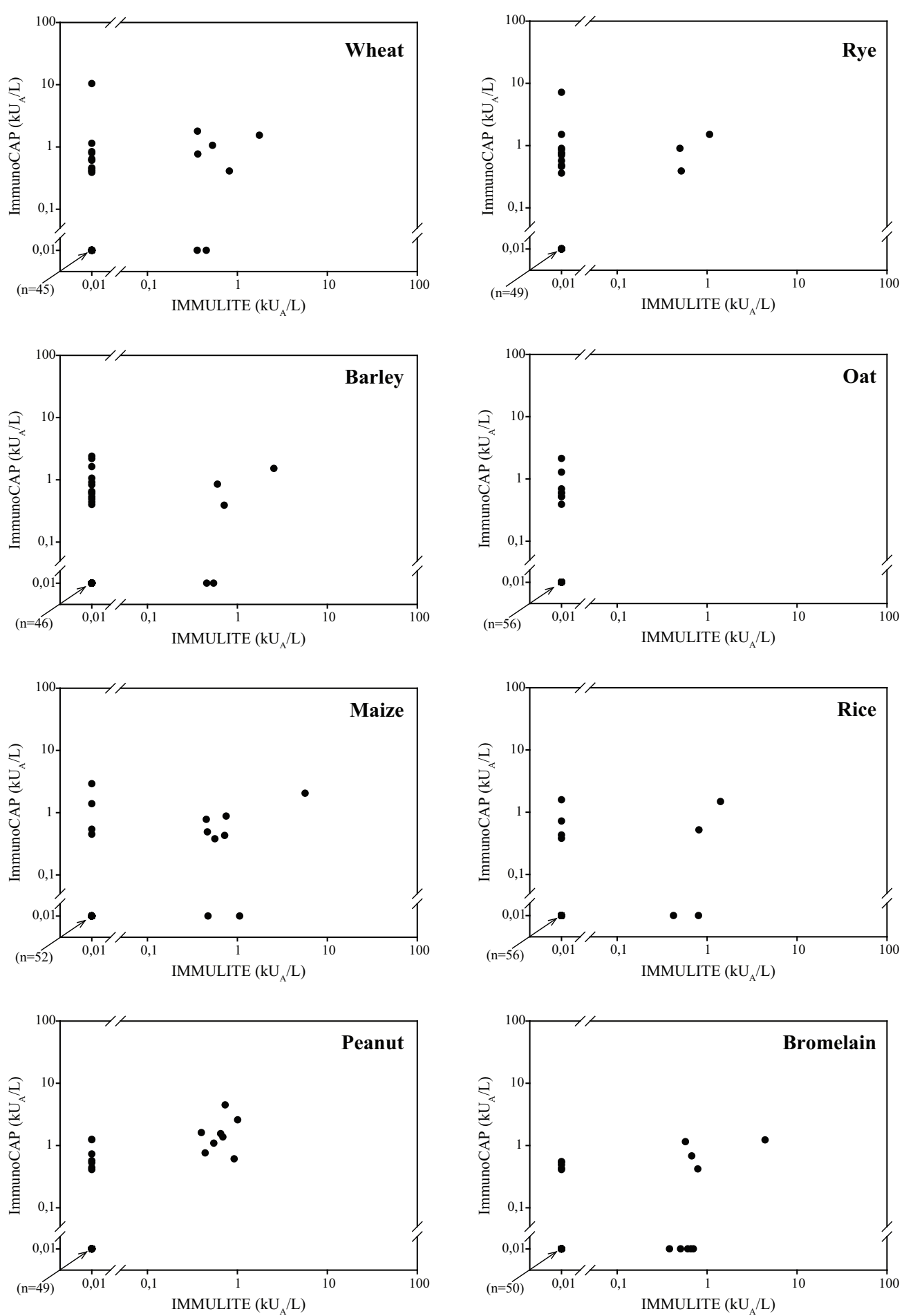

Figure 2 Quantitative relation of slgE against the different cereals, peanut and bromelain. Immulite is plotted against ImmunoCAP for each cereal, peanut and bromelain on double-log-scale. Values depicted at 0.01 represent values $<0.35 \mathrm{kU}_{\mathrm{A}} / \mathrm{L}$. 
or barley; group II: subjects additionally sensitized to oat, maize or rice and group III: maize-sensitized individuals less dependent on other cereals (Figure 3A-C). In SPT (Figure 3A) 29 of the total of 65 subjects were positive to at least one of the three cereals; wheat, rye or barley. Twenty-four of these were positive to two or more of wheat, rye or barley and of these 18 subjects had a positive skin test to all three aforementioned cereals. Eleven subjects were further sensitized to one or more of the cereals in group II (oat, maize or rice), 7 to two or more and only 3 subjects were sensitized to all 6 cereals.
A

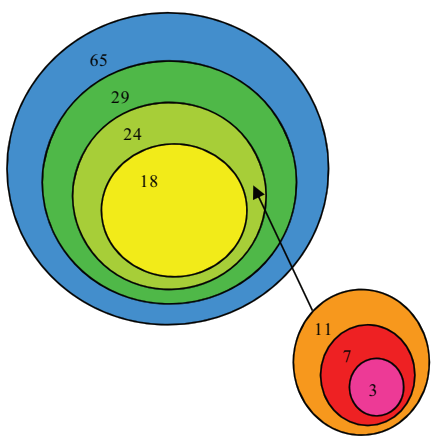

B

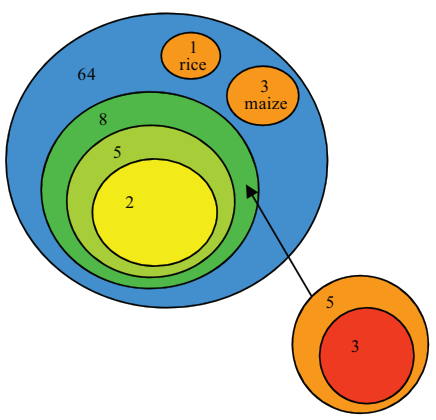

C

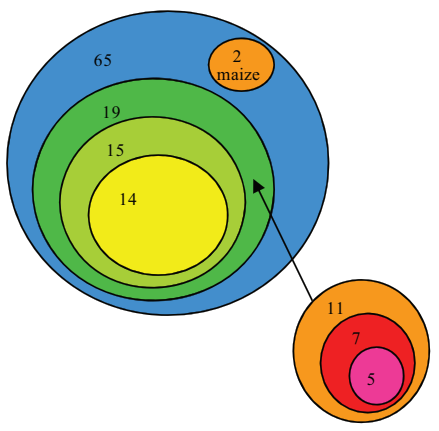

\begin{tabular}{|l|ccccccc|}
\hline CHITEST & $\begin{array}{c}\text { Grass } \\
\text { grass+ } \\
\text { birch }\end{array}$ & Wheat & Barley & R ye & Oat & Maize & Rice \\
\hline Wheat & 0.67 & - & - & - & - & - & - \\
B arley & 0.12 & $2.73 \mathrm{E}-09$ & - & - & - & - & - \\
R ye & 0.67 & $1.24 \mathrm{E}-10$ & $2.73 \mathrm{E}-09$ & - & - & - & - \\
Oat & 0.33 & $1.54 \mathrm{E}-04$ & $3.96 \mathrm{E}-04$ & $1.54 \mathrm{E}-04$ & - & - & - \\
M aize & 1.00 & $1.66 \mathrm{E}-03$ & $3.24 \mathrm{E}-03$ & $1.66 \mathrm{E}-03$ & $2.19 \mathrm{E}-04$ & - & - \\
Rice & 0.54 & $4.47 \mathrm{E}-05$ & $1.33 \mathrm{E}-04$ & $9.95 \mathrm{E}-04$ & $4.65 \mathrm{E}-07$ & $1.62 \mathrm{E}-06$ & - \\
Peanut & 0.02 & 0.01 & 0.14 & 0.43 & $1.14 \mathrm{E}-03$ & 0.01 & $3.18 \mathrm{E}-03$ \\
\hline
\end{tabular}

\begin{tabular}{|l|cccccccc|}
\hline CHITEST & $\begin{array}{c}\text { Grass } \\
\text { grass+ } \\
\text { birch }\end{array}$ & Wheat & Barley & R ye & Oat & Maize & Rice & Peanut \\
\hline Wheat & 0.35 & - & - & - & - & - & - & - \\
B arley & 0.24 & $2.56 \mathrm{E}-07$ & - & - & - & - & - & - \\
R ye & 0.11 & $4.14 \mathrm{E}-07$ & $9.99 \mathrm{E}-05$ & - & - & - & - & - \\
Oat & - & - & - & - & - & - & - & - \\
M aize & 0.03 & $5.87 \mathrm{E}-07$ & $8.23 \mathrm{E}-04$ & $3.66 \mathrm{E}-03$ & - & - & - & - \\
Rice & 0.06 & $2.24 \mathrm{E}-05$ & $2.32 \mathrm{E}-07$ & $9.51 \mathrm{E}-06$ & - & $9.48 \mathrm{E}-05$ & - & - \\
Peanut & $5.92 \mathrm{E}-03$ & $1.54 \mathrm{E}-04$ & 0.05 & $2.68 \mathrm{E}-06$ & - & $1.10 \mathrm{E}-08$ & 0.02 & - \\
Bromelain & 0.51 & $3.72 \mathrm{E}-06$ & $9.99 \mathrm{E}-06$ & $7.26 \mathrm{E}-03$ & - & $1.77 \mathrm{E}-03$ & 0.03 & 0.04 \\
\hline
\end{tabular}

\begin{tabular}{|l|cccccccc|}
\hline CHITEST & $\begin{array}{c}\text { Grass } \\
\text { grass } \\
\text { birch }\end{array}$ & Wheat & Barley & R ye & Oat & Maize & Rice & Penaut \\
\hline W heat & 0.83 & - & - & - & - & - & - & - \\
B arley & 0.61 & $1.38 \mathrm{E}-12$ & - & - & - & - & - & - \\
R ye & 0.50 & $1.48 \mathrm{E}-11$ & $1.86 \mathrm{E}-12$ & - & - & - & - & - \\
Oat & 0.42 & $3.87 \mathrm{E}-07$ & $1.25 \mathrm{E}-07$ & $3.50 \mathrm{E}-08$ & - & - & - & - \\
M aize & 0.02 & $1.15 \mathrm{E}-04$ & $9.80 \mathrm{E}-04$ & $1.80 \mathrm{E}-05$ & $2.89 \mathrm{E}-06$ & - & - & - \\
Rice & 0.08 & $1.56 \mathrm{E}-05$ & $6.82 \mathrm{E}-06$ & $2.68 \mathrm{E}-06$ & $6.75 \mathrm{E}-12$ & $5.27 \mathrm{E}-06$ & - & - \\
Peanut & 0.01 & $6.72 \mathrm{E}-04$ & $2.86 \mathrm{E}-04$ & $1.09 \mathrm{E}-04$ & $1.97 \mathrm{E}-04$ & $1.80 \mathrm{E}-05$ & $2.68 \mathrm{E}-06$ & - \\
Bromelain & 0.01 & 0.03 & $1.60 \mathrm{E}-03$ & 0.01 & $2.09 \mathrm{E}-05$ & $1.80 \mathrm{E}-05$ & $8.43 \mathrm{E}-05$ & $8.26 \mathrm{E}-04$ \\
\hline
\end{tabular}

D No. of patients reacting to peanut:

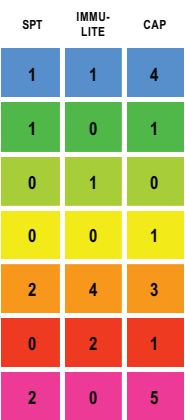

Figure 3 Cluster diagrams and chi $^{2}$-test results of relation between the cereals and peanut. A. Skin prick test. B. Immulite. C. ImmunoCAP. D. Number of patients reacting to peanut in the different clusters. 
The Immulite (Figure 3B) and ImmunoCAP (Figure 3C) showed slightly different but similar patterns. To investigate whether the sensitization to the different foods was random, a chi-square test was performed (Figure $3 \mathrm{~A}-\mathrm{C})$. All cereals were significantly correlated ( $\mathrm{p}<$ 0.05). However, in SPT and ImmunoCAP there was a high association between wheat, rye and barley but in Immulite the cereals were moderately associated, some of this explained by the small number of positives. Cosensitization to birch had an impact on sensitization to cereals, but no correlation was found except for maize in the two SIgE tests. Between peanut and birch there was a significant correlation. In Immulite $38 \%$ of those positive to both peanut and birch were also positive to bromelain, where it was $50 \%$ in ImmunoCAP. In both tests, those sensitized to all foods (and bromelain) were included in these percentages, indicating that it could be the result of sensitization to cross-reactive carbohydrate determinants (CCD) in these cases.

Reactions to peanut showed a less clear pattern in relation to the cereals. However, ImmunoCAP identified 15 subjects sensitized to peanut, but these appeared to be unrelated to the clusters defined by the cereals (Figure 3D).

Bromelain was used as a marker for CCD that might explain some of the false-positive results in the grass pollen allergic subjects clinically tolerant to cereals and peanut. However, as shown in Figure 4A-B the subjects positive to bromelain were not only those sensitized to all the foods tested. The four subjects that were found positive to bromelain by both methods were the subjects that reacted to all seven foods in ImmunoCAP.

\section{Discussion}

In this study we investigated sIgE-tests and SPT to cereals in grass pollen allergic subjects clinically tolerating cereals. This approach is rare possibly because there has been a strong focus on developing sensitive tests for food allergy, whereas the diagnostic specificity has attracted less attention. Cross-reactivity between pollen and foods is important for some allergens, but for others it is frequently not correlated to clinical food allergy [10,15-17].

Grass pollen allergy is one of the most frequent inhalant allergies with an estimated prevalence around 20\% throughout the world, though it differs geographically $[18,19]$. With an estimated prevalence of grass pollen allergy of $20 \%$ of the general population our data could suggest that 9\% would be positive in SPT for a cereal and $4-7 \%$ in the tests for sIgE. If such test results are used without knowledge of the primary grass sensitization and the low specificity of the diagnostic tests, serious consequences could occur. One aspect is a gross overestimation of cereal allergy prevalence in epidemiological studies, when sensitization is used as a proxy for
$\mathbf{A}$

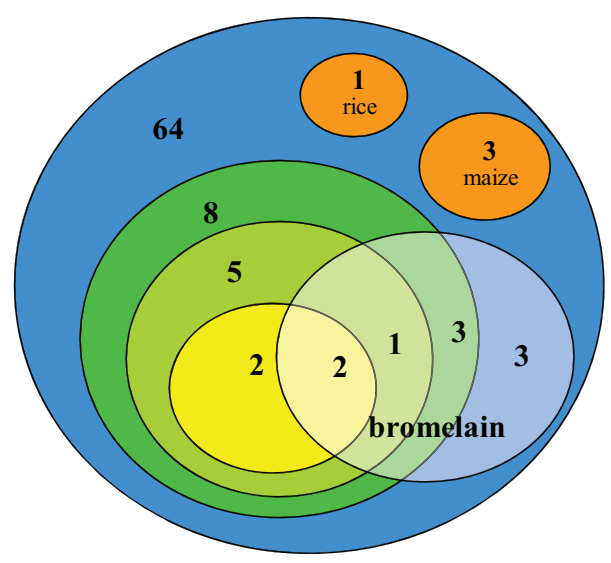

B

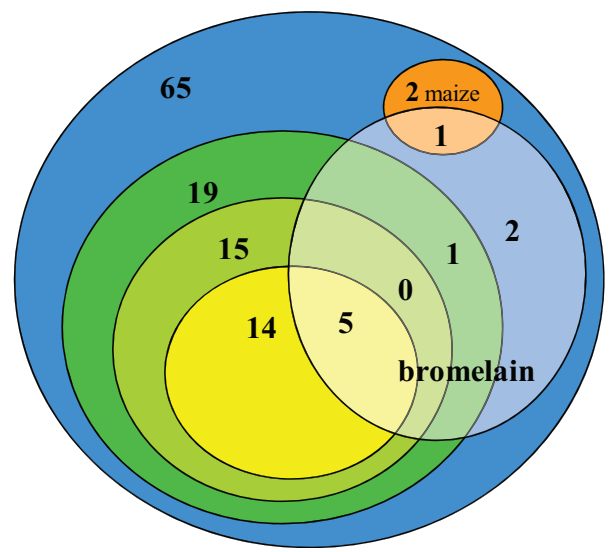

Figure 4 Cluster diagrams showing the distribution of positives to bromelain. Positives to bromelain are shown in the white shaded circles. Colour codes are as in Figure 3. A. Immulite. B. ImmunoCAP.

clinical allergy and proper follow-up is not possible. In several epidemiological studies, strikingly many IgE positives to wheat were in fact found [20]. Another aspect relates to unwarranted dietary restrictions or needless DBPCFC in the daily practice. In the few studies investigating grass pollen allergy and cereal or peanut allergy, the food-allergy-status of the subjects has not been known with certainty $[6,11,17,21]$ or the test groups were small $[8,20]$.

In our study the positive reactions in both SPT and specific IgE tests all occurred in clinically tolerant subjects under the basic assumption that the result of OFC is a true representation of the clinical status. It might be criticized that we did not perform DBPCFC. Instead we used OFC, which we consider adequate since none of the subjects had any history of reacting to the foods tested, and the OFC is anyway recommended subsequent to a negative double-blinded challenge [22]. The reason for using raw cereals was that uncertainty still 
remains as to whether the allergenicity is reduced during heating, as seen for fruits and vegetables cross-reacting with birch pollen, even though Pastorello et al. [16] found that cooking did not induce significant alterations of the protein structure of the true allergens. It could have been interesting to have included a third group of wheat allergic subjects for comparison but this was outside our aim and not easily done due to the low prevalence [23]. Previous studies identified wheat allergens with molecular weight at $12-16 \mathrm{kDa}[3,24]$ and the major grass pollen allergens in group 1 and 5 range from 27-38 kDa [25,26]. Despite this, common epitopes were identified in wheat and grass pollen as high molecular weight proteins $[16,17]$. This suggests that the wheat proteins responsible for wheat food allergy are not the same as the wheat proteins responsible for cross-reactions in grass pollen allergics [16].

In immunological terms the positive reactions are likely to be specific since none of the 20 healthy controls had any positive reactions in any of the tests. In the SPT we used fresh-made suspensions of flour and saline which could be a source of error. Due to the limited characterization of wheat allergens, commercially available extracts are difficult to compare $[3,6]$, and freshly-made suspensions are used in the routine work at our Allergy Clinic. For the standardized inhalation allergen extracts used for SPT a cut off value of $7 \mathrm{~mm}^{2}$ is applied, but is this valid for non-commercial extracts? We would argue that without better characterization and the unsatisfactory diagnostic accuracies of SPT and sIgE-test $[1,6]$; it is interesting to look at any reactions in the test, especially when all 20 healthy controls had negative SPTs-not a single reaction. The comparison of SPT and sIgE is hampered by the use of both non-commercial and commercial extracts. We used the cut off at $0.35 \mathrm{kU}_{\mathrm{A}} / \mathrm{L}$, even though both Immulite and ImmunoCAP are able to measure IgE levels down to $0.1 \mathrm{kU}_{\mathrm{A}} / \mathrm{L}$. Our data shows that a cut off lower than $0.35 \mathrm{kU}_{\mathrm{A}} / \mathrm{L}$ would not benefit the specificity. A cut off at $0.70 \mathrm{kU}_{\mathrm{A}} /$ $\mathrm{L}$ (the inclusion criteria for grass pollen allergics) would improve the specificity, but the consequence for the sensitivity is unknown and was not studied in our design. The false positive rate-in clinical terms-was ranging from 0.20-0.46 of the three tests using the OFC results as the gold standard. The clinically irrelevant sensitization to cereals is often secondary to pollen sensitization showing in the level of positive reactions to grass pollen and wheat. We found that the mean SPT wheal size and the level of sIgE to cereals were much lower than to grass. Matricardi et al. [21] also found this significant difference in the level of sIgE. Furthermore they found that sensitization to wheat most frequently was secondary to pollen sensitization. They did not confirm the observed sensitization to foods by food challenge and therefore cannot conclude about the clinical relevance of these sensitizations. In 1995 Jones et al. [8] found that only 1 of 6 grass pollen allergic subjects tolerating cereals had SPT wheals to cereal grains $>3 \mathrm{~mm}$, whereas all 6 had grass SPT wheals $>3 \mathrm{~mm}$, supporting our assumption that the difference in level of sIgE or wheal size of SPT between the primary and secondary sensitization may indicate the clinical relevance. However, the difference in level of sIgE in general cannot predict the clinical relevance [27], as the cross-reaction to nuts in birch pollen allergic subjects is of high clinical relevance even though the level of SIgE to birch and nuts differ [28].

We saw a cluster of reactions to wheat, rye and barley more frequently than to oat, maize and rice. Wheat, rye and barley are taxonomically from the same tribe, where oat, maize and rice belong to three other tribes, with only oat belonging to the same subfamily as wheat, rye, barley and grass $[8,26]$. This may explain why we see this cluster, which was also observed by Jones et al. [8] with $41-57 \%$ positive to wheat, rye and barley compared with $23-28 \%$ positive to oat, maize and rice. We cannot compare these results directly because some of the patients in Jones' study suffered from wheat allergy.

We also included peanut in spite of the absence of close botanical relation with cereals or grass pollen. Mortz et al. [9] found that 96\% of Danish school children that were sensitized to peanut also had a concomitant reaction to grass pollen. In accordance with our findings they also found a lower sIgE level to peanut than to grass pollen, in grass pollen sensitized subjects with no clinically relevant peanut hyper-sensitization. Guilloux et al. [11] investigated peanut allergic patients some of which were also grass pollen allergic, and found a median sIgE level to peanut $>100 \mathrm{kU}_{\mathrm{A}} / \mathrm{L}$ (Immulite) and $49 \mathrm{kU}_{\mathrm{A}} / \mathrm{L}$ (ImmunoCAP) in the peanut allergic patients, whereas the median peanut sIgE was $0.11 \mathrm{kU}_{\mathrm{A}} /$ $\mathrm{L}$ and $0.68 \mathrm{kU}_{\mathrm{A}} / \mathrm{L}$ respectively, in grass hay fever patients tolerating peanuts. The cross-reaction could also be due to Bet $\mathrm{v} 1$ homologues in peanut, since all the patients positive to peanut were birch pollen sensitized, except one in the ImmunoCAP.

Reactions to CCD offer a good explanation on the observed cross-reactivity between grass pollen and cereals and peanut because of limited clinical relevance of $\mathrm{CCD}$ in the majority of grass-pollen-allergic patients [12,29-31]. Our data with bromelain suggests that CCD might explain the reactions to cereals and peanut in only a few cases, however. It would be of interest to study this in detail by immunoblot assays and inhibition analyses. Constantin and co-workers performed a study of IgE-reactivitiy to components from grass pollen and wheat in different patient groups, of which was also included a grass pollen allergic, anamnestically food 
allergy-negative group of patients [32]. Interestingly, 65\% of these patients reacted to wheat flour in ImmunoCAP, but only $24 \%$ of the patients reacted to a wheat component (profilin), leaving the majority of the false-positive reactions to wheat unexplained. One could speculate that procalcin-another grass pollen pan-allergen-could also participate as a non-clinical relevant allergen [33].

It could be anticipated that the progress in wheat allergy diagnostics where single allergens responsible for wheat food allergy and baker's asthma are being characterized $[1,3,4,24,32-34]$ may improve the specificity of such tests compared with whole extracts.

In conclusion, grass pollen allergic patients with proven food tolerance may express significant sensitization (albeit depending on the test system) to cereals and peanut. Overall $45 \%, 19 \%$ and $32 \%$ reacted to one or more cereals in SPT, Immulite and ImmunoCAP, with wheat, rye and barley causing the most frequent reactions. Likewise, peanut caused $9 \%, 13 \%$ and $23 \%$ false positive reactions. Negative food challenges for exclusion of clinical allergy are occasionally required in routine clinical work and clearly in epidemiological studies.

\section{Abbreviations \\ SPT: skin prick test; OFC: open food challenge; $\mathrm{FEV}_{1}$ : Forced expiratory volume $1^{\text {st }}$ second; slgE: specific immunoglobulin E; CCD: cross-reactive carbohydrate determinants; DBPCFC: double-blind; placebo-controlled food challenge.}

\section{Acknowledgements}

We thank the staff at the Allergy Clinic, Copenhagen University Hospital, for good collaboration. Source of founding: Siemens Ltd.

\section{Authors' contributions \\ MM carried out the clinical study, recruitment of study population, data acquisition and analysis, participated in slgE measuring, designed the case report forms and drafted the manuscript. HJS was responsible for the preparation and conduction of the oral food challenges and participated in revising the manuscript. HJM had the clinical responsibility and participated in coordination of the clinical study and manuscript revising. LKP designed the study, wrote the protocol and participated in data analysis and manuscript revising. All authors have read and approved the final manuscript.}

\section{Competing interests}

The authors declare that they have no competing interests.

Received: 15 September 2011 Accepted: 9 December 2011 Published: 9 December 2011

\section{References}

1. Inomata N: Wheat allergy. Curr Opin Allergy Clin Immunol 2009, 9:238-43.

2. Baur X: Baker's asthma: causes and prevention. Int Arch Occup Environ Health 1999, 72:292-6.

3. Armentia A, Rodriguez R, Callejo A, Martin-Esteban M, Martin-Santos JM, Salcedo G, Pascual C, Sanchez-Monge R, Pardo M: Allergy after ingestion or inhalation of cereals involves similar allergens in different ages. Clin Exp Allergy 2002, 32:1216-22.

4. Tatham AS, Shewry PR: Allergens to wheat and related cereals. Clin Exp Allergy 2008, 38:1712-26.

5. Palosuo K: Update on wheat hypersensitivity. Curr Opin Allergy Clin Immunol 2003, 3:205-9.
6. Sampson HA: Utility of food-specific lgE concentrations in predicting symptomatic food allergy. J Allergy Clin Immunol 2001, 107:891-6.

7. Scibilia J, Pastorello EA, Zisa G, Ottolenghi A, Bindslev-Jensen C, Pravettoni V, Scovena E, Robino A, Ortolani C: Wheat allergy: a doubleblind, placebo-controlled study in adults. J Allergy Clin Immunol 2006, 117:433-9.

8. Jones SM, Magnolfi CF, Cooke SK, Sampson HA: Immunologic crossreactivity among cereal grains and grasses in children with food hypersensitivity. J Allergy Clin Immunol 1995, 96:341-51.

9. Mortz CG, Andersen KE, Bindslev-Jensen C: The prevalence of peanut sensitization and the association to pollen sensitization in a cohort of unselected adolescents-The Odense Adolescence Cohort Study on Atopic Diseases and Dermatitis (TOACS). Pediatr Allergy Immunol 2005, 16:501-6.

10. Vieths $S$, Scheurer $S$, Ballmer-Weber B: Current understanding of crossreactivity of food allergens and pollen. Ann N Y Acad Sci 2002, 964:47-68

11. Guilloux L, Morisset M, Codreanu F, Parisot L, Moneret-Vautrin DA: Peanut allergy diagnosis in the context of grass pollen sensitization for 125 patients: roles of peanut and cross-reactive carbohydrate determinants specific IgE. Int Arch Allergy Immunol 2009, 149:91-7.

12. van der Veen MJ, van RR, Aalberse RC, Akkerdaas J, Koppelman SJ, Jansen HM, van der Zee JS: Poor biologic activity of cross-reactive lgE directed to carbohydrate determinants of glycoproteins. J Allergy Clin Immunol 1997, 100:327-34.

13. Dreborg S, Foucard T: Allergy to apple, carrot and potato in children with birch pollen allergy. Allergy 1983, 38:167-72.

14. Poulsen LK, Liisberg C, Bindslev-Jensen C, Malling HJ: Precise area determination of skin-prick tests: validation of a scanning device and software for a personal computer. Clin Exp Allergy 1993, 23:61-8.

15. Bindslev-Jensen C, Poulsen LK: Some limitations in the use of specific lgE in the diagnosis of food hypersensitivity. Monogr Allergy 1996, 32:216-20.

16. Pastorello EA, Farioli L, Conti A, Pravettoni V, Bonomi S, lametti S, Fortunato D, Scibilia J, Bindslev-Jensen C, Ballmer-Weber B, Robino AM, Ortolani C: Wheat IgE-mediated food allergy in European patients: alphaamylase inhibitors, lipid transfer proteins and low-molecular-weight glutenins. Allergenic molecules recognized by double-blind, placebocontrolled food challenge. Int Arch Allergy Immunol 2007, 144:10-22.

17. Sander I, Raulf-Heimsoth M, Duser M, Flagge A, Czuppon AB, Baur X: Differentiation between cosensitization and cross-reactivity in wheat flour and grass pollen-sensitized subjects. Int Arch Allergy Immunol 1997, 112:378-85.

18. Chinn S, Burney P, Sunyer J, Jarvis D, Luczynska C: Sensitization to individual allergens and bronchial responsiveness in the ECRHS. European Community Respiratory Health Survey. Eur Respir J 1999, 14:876-84

19. Plaschke P, Janson C, Norrman E, Bjornsson E, Lundback B, Lindholm N, Rosenhall $L$, Jarvholm B, Boman G: Skin prick tests and specific IgE in adults from three different areas of Sweden. Allergy 1996, 51:461-72.

20. Zuidmeer L, Goldhahn K, Rona RJ, Gislason D, Madsen C, Summers C, Sodergren E, Dahlstrom J, Lindner T, Sigurdardottir ST, McBride D, Keil T: The prevalence of plant food allergies: a systematic review. J Allergy Clin Immunol 2008, 121:1210-8.

21. Matricardi PM, Bockelbrink A, Beyer K, Keil T, Niggemann B, Gruber C, Wahn U, Lau S: Primary versus secondary immunoglobulin E sensitization to soy and wheat in the Multi-Centre Allergy Study cohort. Clin Exp Allergy 2008, 38:493-500.

22. Bindslev-Jensen C, Ballmer-Weber BK, Bengtsson U, Blanco C, Ebner C, Hourihane J, Knulst AC, Moneret-Vautrin DA, Nekam K, Niggemann B, Osterballe M, Ortolani C, Ring J, Schnopp C, Werfel T: Standardization of food challenges in patients with immediate reactions to foods-position paper from the European Academy of Allergology and Clinical Immunology. Allergy 2004, 59:690-7.

23. Osterballe M, Hansen TK, Mortz CG, Host A, Bindslev-Jensen C: The prevalence of food hypersensitivity in an unselected population of children and adults. Pediatr Allergy Immunol 2005, 16:567-73.

24. Weichel M, Glaser AG, Ballmer-Weber BK, Schmid-Grendelmeier P, Crameri R: Wheat and maize thioredoxins: a novel cross-reactive cereal allergen family related to baker's asthma. J Allergy Clin Immunol 2006, 117:676-81.

25. Mohapatra SS, Lockey RF, Shirley S: Immunobiology of grass pollen allergens. Curr Allergy Asthma Rep 2005, 5:381-7. 
26. Weber RW: Cross-reactivity of pollen allergens. Curr Allergy Asthma Rep 2004, 4:401-8.

27. Keet CA, Matsui EC, Dhillon G, Lenehan P, Paterakis M, Wood RA: The natural history of wheat allergy. Ann Allergy Asthma Immunol 2009, 102:410-5.

28. Hansen KS, Ballmer-Weber BK, Sastre J, Lidholm J, Andersson K, Oberhofer H, Lluch-Bernal M, Ostling J, Mattsson L, Schocker F, Vieths S, Poulsen LK: Component-resolved in vitro diagnosis of hazelnut allergy in Europe. J Allergy Clin Immunol 2009, 123(5):1134-1141.

29. van Ree R: Carbohydrate epitopes and their relevance for the diagnosis and treatment of allergic diseases. Int Arch Allergy Immunol 2002, 129:189-97.

30. Mari A, Ooievaar-De HP, Scala E, Giani M, Pirrotta L, Zuidmeer L, Bethell D, van RR: Evaluation by double-blind placebo-controlled oral challenge of the clinical relevance of IgE antibodies against plant glycans. Allergy 2008, 63:891-6.

31. van Ree R: Clinical importance of cross-reactivity in food allergy. Curr Opin Allergy Clin Immunol 2004, 4:235-40.

32. Constantin C, Quirce S, Poorafshar M, Touraev A, Niggemann B, Mari A, Ebner C, Akerström H, Heberle-Bors E, Nystrand M, Valenta R: Micro-arrayed wheat seed and grass pollen allergens for component-resolved diagnosis. Allergy 2009, 64(7):1030-7.

33. Asero R, Jimeno L, Barber D: Preliminary results of a skin prick test-based study of the prevalence and clinical impact of hypersensitivity to pollen panallergens (polcalcin and profilin). J Investig Allergol Clin Immunol 2010, 20(1):35-8.

34. Ito K, Futamura M, Borres MP, Takaoka Y, Dahlstrom J, Sakamoto T, Tanaka A, Kohno K, Matsuo H, Morita E: IgE antibodies to omega-5 gliadin associate with immediate symptoms on oral wheat challenge in Japanese children. Allergy 2008, 63:1536-42.

doi:10.1186/2045-7022-1-15

Cite this article as: Martens et al: Sensitization to cereals and peanut evidenced by skin prick test and specific IgE in food-tolerant, grass pollen allergic patients. Clinical and Translational Allergy 2011 1:15.

\section{Submit your next manuscript to BioMed Central} and take full advantage of:

- Convenient online submission

- Thorough peer review

- No space constraints or color figure charges

- Immediate publication on acceptance

- Inclusion in PubMed, CAS, Scopus and Google Scholar

- Research which is freely available for redistribution

Submit your manuscript at www.biomedcentral.com/submit
Ciomed Central 